Valerie Wurm

\title{
DISTINGUISHING SEMANTIC COMPONENTS OF ATTITUDE VERBS VIA THE GERMAN MODIFIER GENAU
}

\begin{abstract}
This paper presents novel data from German: certain attitude verbs such as wissen ('know') as well as all verbs of perception are compatible with the modifier genau ('exactly') which is usually associated with expressing precision. When modifying wissen in declarative embedding contexts, genau seems to convey that the relevant attitude holds to a specifically high degree which poses a problem for the classical semantic approach to wissen. On the traditional view, wissen is analyzed as a relation that evaluates a proposition w.r.t. a subject's belief worlds and requires that it holds in all of these worlds-i.e., it is an 'all-or-nothing' concept. Accordingly, any kind of strengthening of this relation should be impossible. Based on LEWIS (1996), I will show that the modifier's semantic impact in the use described here can be explained as a manipulation of the set of possible worlds incompatible with the proposition that is known. Thus, I will argue that certain attitude verbs cannot only be sensitive to belief worlds but also to alternatives thereof.
\end{abstract}

\section{KEYWORDS}

knowledge; attitude verbs; perception verbs; precision; alternatives

\section{Introduction}

The German modifier genau 'exactly' is usually associated with expressing precision, e.g., when modifying numerals as in (1).

(1) Cat besitzt genau dreißig Schweine.

Cat owns GENAU thirty pigs

'Cat owns exactly thirty pigs.'

1 As there is no consistent English equivalent of genau in the different contexts I will use exactly if it fits and paraphrase it differently otherwise. 
However, genau can also combine with certain propositional attitude verbs-like wissen 'know', (2a)-as well as all perception verbs, e.g. (2b).
(2) a. Ich weiß genau, dass es draußen regnet. I know GENAU that it outside rains 'I know for sure that it is raining outside.'
b. Brit hört genau, dass das keine echte Stradivari ist. Brit hears GENAU that this no real Stradivarius is 'Brit definitely hears that this is not a real Stradivarius.'

Intuitively, the modifier seems to add extra "strength" or "reliability" of the relevant attitude or perception. However, it is unclear how to combine this intuition with the traditional semantic analysis of wissen. The aim of this paper is twofold: first, I will outline the problem based on new data, second, I will provide a paraphrase that captures the impact of genau in the use of interest. It will turn out that this approach will force an essential revision of the semantics of wissen. As the problem presented is completely new, this paper will not go beyond a paraphrase and leave a compositional analysis based on this paraphrase for future work.

The paper is structured as follows: Section 2 briefly outlines existing analyses of wissen, and the modifier exactly (as the English counterpart of genau in its "precision" use). Section 3 focuses on the distribution of the modifier in the context of attitude and perception predicates and identifies a relevant feature shared by all verbs it combines with. Furthermore, two different readings that arise in such contexts are distinguished. In Section 4 the foundation for the paraphrase will be laid out based on contexts that allow for modified wissen. Here, the claim that genau in these uses modifies the set of worlds to be considered is motivated and related to the notion of "ignorable worlds" from Lewis (1996). Section 5, finally, provides a paraphrase for a revised lexical entry for wissen and, based on this, a paraphrase capturing the contribution of genau in these contexts. Section 6 concludes.

\section{Existing analyses}

Due to the lack of existing analyses for German wissen, I adapt those for its English counterpart know. I will argue that the compatibility of wissen and genau, resulting in an apparent strengthening of the attitude, raises a problem for the traditional approach. An alternative account of Lewis (1996) that significantly departs from the classical view by including an additional ingredient that is crucial in the light of the problem raised in this paper will be addressed in Section 4. 


\subsection{Classical approach to know}

Traditionally, i.e., based on HinTikкA (1969), know with declarative complements is taken to denote a relation between the referent $x$ of the matrix subject and the content of the embedded clause $p$. It requires that $x$ believes $p$ and furthermore presupposes the truth of $p$; see KIPARSKY - KIPARSKY (1970). Supplemented with the notion of evidence included in the "classical" view of knowledge as justified true belief, this yields the lexical entry in (3) for wissen:

(3) $\left[\right.$ wissen $\left.\left._{D E C L}\right]\right]^{w}=\left[\lambda p \cdot \lambda x: p(w)=1 . \forall w^{\prime} \in\left\{w^{\prime \prime}: w^{\prime \prime}\right.\right.$ is a belief world of $x$ in $\left.w\right\}$ $\left(p\left(w^{\prime}\right)=1\right) \& x$ has enough evidence for $p$ in $\left.w\right]$

Know $w_{Q}$ the interrogative embedding construction, is usually derived from know ${ }_{D E C L}$ (KARTtunen 1977). The intuition here is that $x$ knows $Q$ is true iff $x$ knows the true answer to the question expressed by $Q$ and thus resembles $x$ knows that $p$. The corresponding lexical entry for German wissen ${ }_{Q}$ thus looks roughly as in (4).

(4) $\left[\left[\text { wissen }_{Q}\right]\right]^{w}=\lambda Q . \lambda x \forall p \in Q\left(p(w)=1 \rightarrow\left[\left[\right.\right.\right.$ wissen $\left.\left.\left._{D E C L}\right]\right](p)(x)\right)$

Traditional analyses thus take the meaning of wissen to be an all-or-nothing concept, hence we should not be able to appeal to degrees of "strength" or "reliability".

\subsection{Existing analyses of exactly}

In this section I will give a brief overview of existing claims about the semantics of exactly which constitutes the counterpart of German genau in its precision expressing use, e.g., when modifying numerals, as in (5).
(5) Auf dieser Insel lebt/leben
genau $1 / 77 / 100$
Hunde/e.
on this island lives/live GENAU $1 / 77 / 100 \mathrm{dog} / \mathrm{s}$
'There is/are exactly $1 / 77 / 100 \mathrm{dog} / \mathrm{s}$ on this island.'

The assumptions about the semantic contribution of the modifier in this use depend on the assumptions regarding the meaning of number words. If number words are attributed a non-upper-bounded lexical meaning, i.e., five expresses 'five or more', see HoRn (1972), LEvinson (1983), then the function of the modifier could simply be assumed to map this meaning to a bounded meaning ('five and not more than five'). If, however, the lexical meaning of number words is taken to be bounded, i.e., five expresses 'five and not more than five', then the modifier's semantic contribution is not obvious. GEURTS (2006), who assumes such a bounded reading, thus argues that exactly is semantically empty. Following LASERSOHN (1999), Geurts sees the function of genau in reducing the context depending pragmatic slack observed for expressions like 3 oclock or round numbers. (However, he does not spell this idea out in detail and it is unclear to me how to combine it with the presumed semantic 
vacuity of exactly.) Somewhat connected to the latter point, SAUERLAND - STATEVA (2007) suggest that number words are evaluated on scales whose granularity is dependent on contextually provided parameters of interpretation. Modifiers like exactly or approximately can set this parameter to the finest or coarsest level, respectively, that the context makes available.

While there is no doubt that round numbers can exhibit an imprecise use, nonround numbers like 77 usually do not allow for imprecision. Nevertheless, (5) shows that exactly 77 is a just as felicitous as exactly 100. This poses a problem for those analyses where exactly is assumed to reduce pragmatic slack or set a granularity parameter: If there is no imprecision in the first place, the modifier should be redundant. While this issue is of interest for the problem raised in this paper, I will not discuss it in greater detail for reasons of space.

Disregarding the details, the crucial point is that it is not obvious in what sense wissen is a degree denoting expression and how genau could have access to a scale in this case. ${ }^{2}$ Still, one way to obtain some kind of gradeability is to claim that the modifier strengthens specific semantic components of wissen. The next section thus considers two obvious candidates for such components: evidence and certainty. Although I show in Section 4 that evidence plays an indirect role w.r.t. the modifier's impact, I argue that it is not a basic semantic component that is manipulated and that a more abstract representation is needed.

\subsection{Evidence and certainty}

Based on the intuition that genau adds extra strength or reliability, I consider evidence and certainty as candidates for the component targeted by the modifier. Generally, if this idea was on the right track, we would assume that i) the modifier only combines with verbs that contain one of these particular components and ii) all predicates containing one of these components allow genau-modification. However, both predictions will be shown to be wrong. Evidence is ruled out by two observations: i) the (old) observation that having enough evidence is a requirement even of unmodified instances of wissen: (6b) cannot be uttered felicitously in scenario (6a).

2 An anonymous reviewer points out that literature on speaker-oriented precision predicates (e.g., BeLtrama 2018 on the pragmatic use of totally) or metalinguistic comparison (e.g., MoRZYCKI 2011) might provide helpful insights; in both cases-as is it the case for genau wissen-an expression that is usually assumed to appeal to degrees attaches to an expression that is not gradable. Beltrama analyses pragmatic totally as an operator that manages the Common Ground (CG), conveying that from the speaker's perspective, there is no other option than adding $p$ to the CG. MORZYCKI (2011), building on what Lasersohn calls 'Halos', analyses metalinguistic comparatives in terms of alternatives: he suggests that metalinguistic more in $x$ is more a than $b$ compares degrees of imprecision, i.e. the size of halos that consist of alternatives, and requires that a is closer to being true of $x$ than $b$. In principle, both, a metalinguistic analysis as well as a speaker-oriented requirement on the CG are imaginable for genau wissen; but I do not quite see how a degree that has to be stipulated, nor an operator managing the CG, can account for the restrictions of genau, e.g., its incompatibility with other attitude verbs like glauben (cf. Section 3 ). 
(6) a. SCEnARio: There was a bank robbery. Paul witnessed it from across the street. He heard people screaming and saw three persons running out of the bank. Paul thinks that one of them, a guy with a blue hat, looks evil and assumes him to be the criminal. He did not see or hear anything else. His friend Marge reports to the police:

b. \#Paul knows that the guy with the blue hat robbed the bank. ${ }^{3}$

ii) erinnern 'remember', which allows genau-modification as shown in (7), intuitively does not involve evidence:

(7) Lisa erinnert sich genau, dass es gestern geregnet hat. Lisa remembers REFL GENAU that it yesterday rained has 'Lisa definitely remembers that it rained yesterday.'

Based on this, I exclude the possibility that genau relates directly to the "evidencecomponent". If, on the other hand, certainty was the relevant component, we would predict sicher sein 'be certain'-which obviously containing that component-to be compatible with the modifier. (8) shows this prediction to be false.

(8) "Ich bin genau sicher, dass die Lisa zur Party kommt.
I am GENAU certain that the Lisa to party comes
'I am GENAU certain that Lisa is going to come to the party.'

Hence, the component targeted by genau cannot be certainty either. But which ingredient is it then, that is responsible for the compatibility with the modifier? To be able to explore this question in greater detail, I will provide an overview of the genau-compatible verbs in the next section.

\section{Distribution}

If there is a component that is crucial w.r.t. whether a verb can combine with genau, it should be possible to distinguish a set of verbs based on this property. Thus, the current section investigates the class of verbs that can be modified by genau and discusses those that unexpectedly do not fall into this class. After that, I identify an independent property shared by all members of this set. Finally, I argue that the modifier exhibits two different readings when occurring in the context of such predicates-a relevant distinction as I am only providing a paraphrase for one reading. 


\subsection{Verbs compatible with genau}

Apart from wissen and erinnern, several other attitude verbs allow for the modifier when embedding declaratives (henceforth know-type predicates), as shown in (11):

(11) Danger versteht / weiß / merkt / genau, dass er

Danger understands / knows / is-aware-of / GENAU that he nicht ins Bett darf.

not in bed can

'Danger definitely understands/knows/is-aware-of that he is not allowed to enter the bed.'

In terms of compatibility with genau, those predicates fall into a class with perception verbs, all of which can combine with the modifier, (12a)-and, surprisingly, not in a class with other attitude verbs, (12b).

(12) a. Brit hört / sieht / riecht / genau, dass ein Schwein
Brit hears / sees / smells / GENAU that a pig
im Zimmer ist.
in room is
'Brit definitely hears/sees/smells that there is a pig in the room.'4
b. "Ruth vergaß / bedauert / glaubt / bereut genau, dass es
Ruth forgot / regrets / believes / regrets / GENAU that it
gestern regnete.
yesterday rained
'Ruth forgot/regrets/believes GENAU that it was raining yesterday.'

Crucially, using the compatibility of genau as a diagnostic, verbs that are often treated on a par behave dissimilar (as wissen and glauben), whereas others that are normally not treated together, pattern alike (as wissen and hören). I will now extract an independent property via which this new class can be distinguished.

\subsection{Distinguishing a new class of verbs}

This section aims to narrow down the class of verbs that combine with genau further by identifying an independent way of characterizing its members. I suggest that for all of them the following holds:

i) From every statement of the form ' $x$ perception-verb that $p$ ' or 'know-type predicate that $p$ ' it follows that $x$ knows that $p$.

ii) $x$ knows that $p$ holds at the time the sentence is evaluated and judged true.

iii) $x$ knows that $p$ is not presupposed. ${ }^{5}$

4 As the English translations in (11) and (12a) show, genau cannot be translated by exactly when modifying know-type or perception verbs in declarative contexts. While some English native speakers suggested translations as definitely or for sure, there seems to be no agreement on the English counterpart of genau in this use.

5 A second way of formulating this generalization is to replace iii) with the requirement of 
Glauben is excluded from the generalization via i), i.e., $x$ believes that $p$ does not entail $x$ knows that $p$. Bereuen/bedauern is excluded via iii), i.e., $x$ regrets that $p$ presupposes $x$ knows that $p .{ }^{6}$ This distinction is illustrated in (13): while all know-type and perception verbs mentioned are compatible with iii) as none of them presupposes $x$ knows that $p$, (13a) vs. (13b), in the case of bereuen/bedauern the know-part is presupposed, (13c) vs. (13d). Presupposed and asserted content differ in terms of their projection behavior: while the former projects, e.g., being preserved under negation, the latter does not (LANGENDOEN - SAVIN 1971).

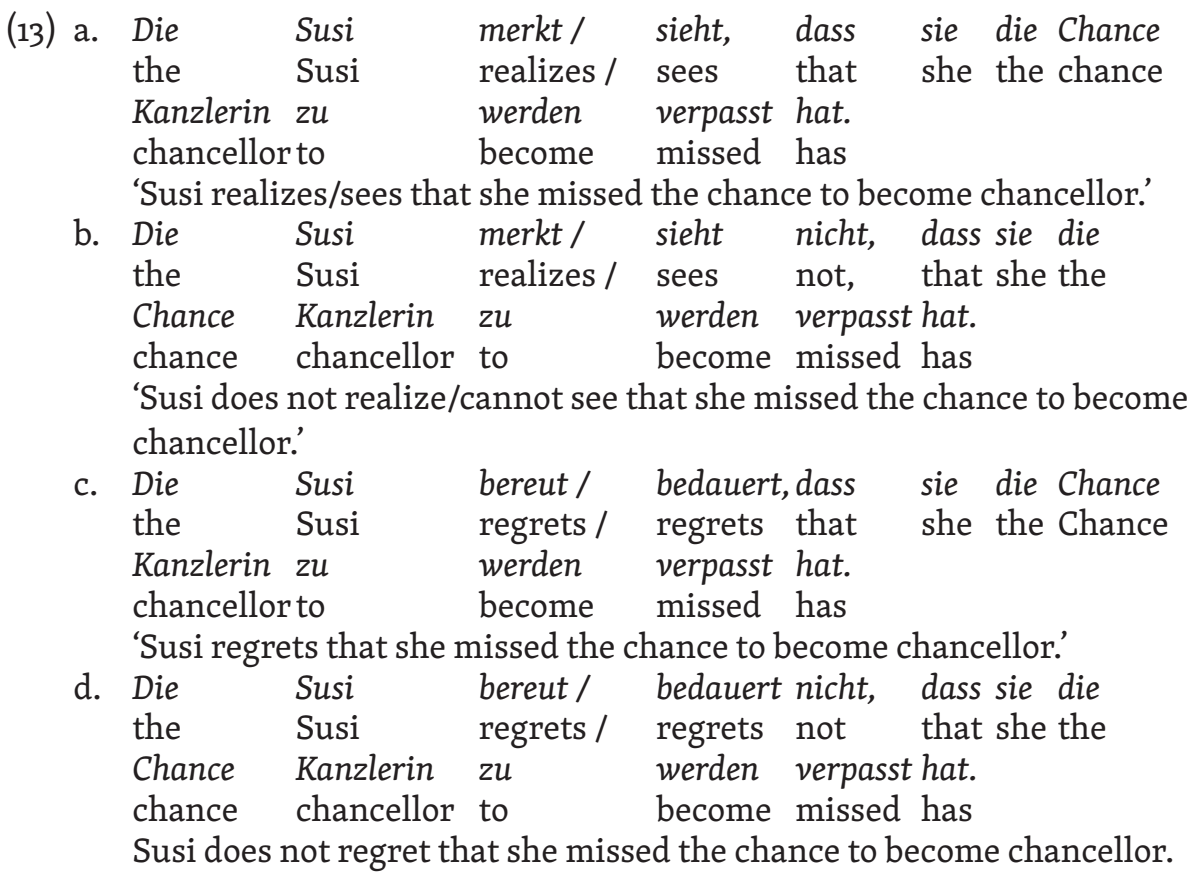

The non-negated sentences in (13a) and (13c) entail knowledge, i.e., the inference 'Susi can rule out every alternative that contradicts the fact that she missed the chance to become chancellor' holds. Yet, if the matrix sentences are negated, this entailment only survives in (13d), where bereuen/bedauern is negated, but not in (13b), where the know-type or perception verb is negated. This contrast suggests that $x$ knows that $p$ is asserted in (13a) but presupposed in (13c).

embedding polar questions. Vergessen is the only verb incompatible with genau that embeds polar question, though, it is excluded from the generalization via ii).

6 Emotive and cognitive factives are known to differ in several aspects (e.g., KARTUNNEN 1971). As pointed out by an anonymous reviewer, there is recent experimental work (e.g., DJÄRV et al. 2018) that provides interesting new insights w.r.t. this distinction. Though, while the projection behavior of the embedded clause is discussed extensively in the literature, I am not aware of any discussion of the projection behavior of the "know-part" of the matrix clause. 


\subsection{Embedded interrogatives}

This section distinguishes an additional reading of genau that emerges in question embedding contexts from the one investigated in this paper. All verbs compatible with genau also embed wh-questions and can appear with the modifier in this configuration as well:

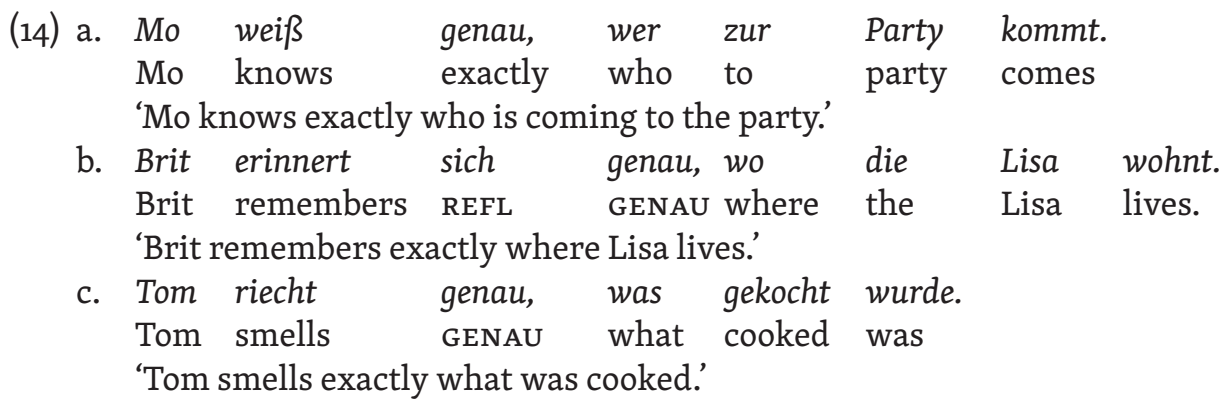

I claim that the modifier exhibits two different readings when occurring in the matrix clause of a question embedding construction. This paper will focus on only one of them, namely the one that emerges in declarative embedding contexts. I motivate this distinction based on distributional variation of the modifier in declarative embedding and wh-embedding contexts, respectively.

The first difference concerns the licensing of the counterpart of genau, ungefähr 'approximately' and the negated modifer. As opposed to embedded declaratives, (15c), when a wh-question is embedded, ungefähr and negated genau are licensed (15b), as it is the case when modifying numerals (15a):

(15) a. Cat besitztungefähr / nicht genau dreißigSchweine.

Cat owns approximately not GENAU thirty pigs

'Cat owns approximately / not exactly thirty pigs.'

b. Mo weiß ungefähr/ nichtgenau, wer zur

Mo knowsUNGEFÄHR / not GENAU who to partycomes

'Mo knows approximately/does not know exactly who is going to come to the party.'

c. *Danger weiß ungefähr / nicht genau, dass er das nicht darf. Danger knows UNGEFÄHR / not GENAU that he this not may 'Danger knows UNGEFÄHR / does not know GENAU that he is not allowed to do that.'

Another difference w.r.t. embedded questions is that the modifier can appear in the complement clause resulting in a similar meaning, (16a), whereas moving the modifier in declarative contexts yields an ungrammatical result, (16b).7 Additionally, in

7 As an anonymous reviewer points out, there are grammatical instances of genau in embedded declaratives: 
wh-embedding contexts, the modifier can occur in both positions-the matrix clause and the embedded wh-question-simultaneously without being redundant (16c).

(16) a. Brit erinnert sich, wo genau Lisa wohnt.

Brit remembersREFL where GENAU Lisa lives

'Brit remembers where Lisa exactly lives.'

b. "Ruth weiß, dass genau es regnet.

Ruth knows that GENAU it rains.

'Ruth knows that GENAU it is raining.'

c. Danger riecht genau, wo genau der Knochen vergraben ist. Danger smells GENAU where GENAU the bone buried is 'Danger can definitely smell where exactly the bone is buried.'

In (16a) only one reading is available-which will not be investigated in this paper. (14a), where genau occurs in the matrix clause and a wh-question is embedded, is ambiguous. The following table sums up the distributional differences w.r.t. the embedding contexts:

\begin{tabular}{|l|l|l|l|l|}
\hline & genau & ungefähr & negated genau & embedded genau \\
\hline declarative & yes & no & no & no \\
\hline wh-question & yes & yes & yes & yes \\
\hline numeral & yes & yes & yes & - \\
\hline
\end{tabular}

\section{Table 1}

To sum up, the modifier has two different readings when combining with knowtype or perception predicates in the matrix clause: $i$ ) the one where the attitude is directly modified-the relevant one for the aim of this paper ("d-reading"-for declarative-from now) and ii) one where the complement is modified. In wh-question contexts both readings are available, while the one where the wh-question is modified is the prominent one and intuitively targets the granularity of the set of answers that are denoted by it. Here, as suggested by the English paraphrases in (14), genau can be translated as exactly and, regarding its impact, perhaps be connected

i) Ruth weiß, dass Lisa genau in dieser Stadt wohnt.
Ruth knows that Lisa GENAU in this city lives
'Ruth knows that Lisa is living in exactly this city.'

In such cases, though, the modifier is licensed independently of embedding and concerns questions that go beyond the scope of this paper. Nevertheless, such occurrences raise a very interesting issue-actually, genau seems to be quite unlimited w.r.t. the type of phrase it attaches to. Thus, I think that such and related instances (as genau dasselbe 'exactly the same') are definitely worth investigating and can possibly be related to the questions raised in this paper in future work.

8 Polar questions display an interesting behavior: they allow for genau and negated genau, while ungeführ and embedded genau is ruled out. 
to the precision expressing version in future work (which is also supported by the similar pattern visible in the table above).

In declarative contexts, only the d-reading is available. If or how this use can be connected to precision genau remains unclear for now, although there seems to be at least one parallel: just as in genau 77 'exactly 77', where the modifier's impact is unclear given 77 is already precise, a similar question emerges w.r.t wissen: there is no component in the classical semantics of wissen that is accessible for genau-modification.

\section{Towards a paraphrase}

After having identified the class of verbs compatible with genau and distinguished two readings, I turn to the question of the component targeted by the modifier in the d-reading. As I excluded evidence and certainty for the semantic components necessary for the availability of the modifier, I will argue for the presence of the more abstract property of considering alternative worlds. It will turn out that evidence plays a crucial role, however, not in terms of a basic semantic component of the lexical entries of the relevant verbs. Consider the following dialog where genau in the d-reading is licensed:

(18) a. SCEnARio: On Saturdays at 12 Carla, Anna and Berta meet and play soccer. Whenever Lisa is in Vienna, she joins them. This week, C, A and B arrive early. At 11:50 they discuss whether they should wait or start playing.

b. A: Does anyone know whether Lisa is coming today?

c. B: Ja, ich weiß, dass sie kommt. yes I know that she comes

'Yes, I know that she is coming.'

d. C: That's impossible, Lisa died yesterday.

e. B: Nein, ich weiß genau, dass sie kommt.9 no I know GENAU that she comes 'No, I definitely know that she is coming.'

(18) shows that the modified construction in (18e) can be used to disagree with a proposition, (18d), that again contradicts a speaker's (B's) knowledge, (18c), and is assumed to be true by the collocutor (Carla)-and it does so by somehow emphasizing the strength or reliability of one's knowledge. This seems compatible with the idea of better evidence: B's utterance in (18e) could be motivated by the visual experience of seeing Lisa approaching them. As I have excluded the possibility that genau directly targets evidence as a semantic component of the lexical entry of

9 Whereas bare wissen is rather odd here, the modifier can be omitted by either putting major stress on wissen, or by adding material that is supposed to corroborate the reliability of the knowledge. The connection to focus is interesting and definitely worth an investigation in future work. 
wissen-based on i) that bare wissen already requires enough evidence and ii) that there are verbs compatible with genau that do not involve evidence-I conclude that what the modifier manipulates has to be a more abstract version of that component. I argue that this component has to do with the consideration of alternative worlds-namely, worlds that are not in the set of the speaker's belief worlds. To illustrate this, let us consider B's belief worlds in the context of (18) and say that B believes the following propositions in $w$ :

(19) Whenever Lisa is in Vienna she joins soccer on Saturdays, Lisa is in Vienna, dead people do not walk, Lisa is alive

Let us furthermore assume that B utters (18d) based on the following evidence:

EVIDENCE 1: Berta sees Lisa approaching them while they are discussing.

I claim that B can utter Ich weiß genau dass $p$ in (18e) because of her being in the position of excluding alternative worlds that resemble her belief worlds w.r.t. various properties, and are counterfactual. In turn, this process of excluding directly depends on her evidence. For illustration consider some salient worlds, some of which are counterfactual:

\begin{tabular}{|c|c|}
\hline $\begin{array}{l}\text { w1: } \\
\text { Lisa came to Vienna yesterday } \\
\text { Dead people do not walk } \\
\text { Lisa died yesterday }\end{array}$ & $\begin{array}{l}\text { w2: } \\
\text { Lisa left Vienna yesterday } \\
\text { Dead people do not walk } \\
\text { Lisa is alive } \\
\text { Someone hacked Lisa's email account and } \\
\text { sent a message to her friend saying that } \\
\text { she is in Vienna }\end{array}$ \\
\hline \begin{tabular}{|l} 
w3: \\
Lisa left Vienna one month ago \\
Dead people do not walk \\
Lisa died yesterday \\
\end{tabular} & $\begin{array}{l}\text { w4: } \\
\text { Lisa came to Vienna three days ago } \\
\text { Dead people do not walk } \\
\text { Lisa is alive }\end{array}$ \\
\hline $\begin{array}{l}\text { w5: } \\
\text { Lisa came to Vienna last month } \\
\text { Dead people do not walk } \\
\text { Lisa is alive }\end{array}$ & $\begin{array}{l}\text { w6: } \\
\text { Lisa came to Vienna a week ago } \\
\text { Dead people do not walk } \\
\text { Lisa died yesterday }\end{array}$ \\
\hline & $\begin{array}{l}\text { Someone hacked Lisa's email account } \\
\text { and sent a message to her friend saying } \\
\text { that she is in Vienna }\end{array}$ \\
\hline
\end{tabular}

\section{Table 2}


Evaluated w.r.t. B's evidence 1 this yields the following: whereas $w 1, w 2, w 3$ and $w 6$ are incompatible with her evidence, w4 and w5 are compatible. Thus, based on Evidence 1 , she can rule out every world in which Lisa is dead. However, if we suppose that B has different evidence, say Evidence 2, and keep constant what she believes in $w$, this pattern changes.

EvidENCE 2: Two days ago, Berta received a message from Lisa saying that she is in Vienna.

Evaluated relative to Evidence 2, only one of the worlds in which it holds that Lisa is dead is incompatible, namely $w_{3}$, whereas $w_{1}, w_{2}, w_{4}, w_{5}$ and $w_{6}$ are compatible. Thus, based on Evidence 2 B can distinguish fewer alternative worlds that are counterfactual w.r.t her belief worlds than she can based on Evidence 1. Crucially, supposing that B has Evidence 2, she could not utter Ich wei $\beta$ genau dass $p$ in the dialogue in (18)-in this case C's utterance in (18d) successfully challenges B's utterance of the form Ich wei $\beta$ dass $p$ in (18c). Importantly, without being challenged, Evidence 2 is intuitively sufficient to utter (18c), though, Evidence 2 is somehow better: based on that, more possible worlds where not- $p$ holds can be excluded.

Thus, I argue the following: i) wissen (and other know-type and perception verbs) cannot only be sensitive to the subject's belief worlds but also to worlds outside of this set; ii) in the case of bare wissen, besides the belief worlds, a limited set of worlds incompatible with what is believed is considered (e.g., worlds like w3); iii) in the case of the modified version, genau induces a widening of this additional set (worlds incompatible with what is believed). As a result, in the case of genau wissen, more worlds are considered and can be sorted relative to the evidence. Thus, the set of counterfactual worlds that can be ruled out as candidates for the actual world is larger, which is responsible for the strengthening effect observed.

Now, the crucial question is: how can this additionally considered worlds that are somehow close to the subject's belief worlds, though potentially incompatible, be described or restricted? Thus, I adapt a related idea from LewIs' (1996) account of knowledge ascription that he builds around the exclusion of possibilities-which, in fact, is incompatible with the traditional semantics of wissen. I make use of Lewis' idea in order to support my suggestion and formulate a paraphrase capturing the semantic contribution of the modifier in the d-reading. As a consequence, these assumptions force a complete revision of the lexical entry for wissen, for which I also provide a paraphrase.

\subsection{Different types of possibilities}

Lewis (1996) assumes that one knows that $p$ if one can exclude every not-p possibility apart from those possibilities that are properly ignored. In order to identify the potentially ignorable possibilities he introduces a number of rules and 
argues that a crucial property of these possibilities is that we do not even think of them. Hence, whenever a possibility is under consideration, it cannot be ignored. He then distinguishes between three classes of possibilities:

TYPE 1: Possibilities that can only be excluded

TYPE 2: Possibilities that can only be ignored

TYPE 3: Possibilities that can either be ignored or excluded

He illustrates these types relative to the question under what circumstances I know that the cat is not in the office $(q)$ can be uttered felicitously. In this case, several possibilities of Type 1 are eliminated by looking around in the office, e.g., the possibility that the cat is on the desk-which has to be excluded and cannot be ignored in order to utter $q$. Type 2 includes, e.g., the possibility that the cat is in fact on the desk but made herself invisible. Such possibilities can never be excluded but always have to be ignored. Type 3, finally, contains, e.g., of the possibility that the cat secretly crawled into the drawer, and thus was not seen when checking the office. A possibility that due to Lewis can be ignored, while $q$ can still be uttered felicitously. Though, it can of course be excluded as well: by checking the drawer. Lewis argues that the more potentially excludable possibilities are excluded, the better the knowledge. Thus, the knowledge that the cat is not in the office is better when the possibility of her having secretly crawled in the drawer is excluded, than when it is ignored.

I submit that this "better knowledge" is what the modifier induces; when combining with a predicate, it widens the set of worlds to be considered insofar as any possibility that falls in Lewis' Type 3 class is under consideration and can thus be excluded. The relation between the exclusion of possibilities and the type of evidence should be obvious: if, using Lewis' example, I know that the cat is not in the office is uttered based on the evidence that the cat sits on the speaker's lap, any world where she is in the drawer can be ruled out-in this case genau is licensed. On the other hand, if the speaker's evidence is based on her checking the room without opening or looking into anything, such worlds cannot be ruled out. (19) shows a dialog that adapts Lewis' example where genau is licensed:

(19) a. A: Do you know where the cat is?

b. B: Ich wei $\beta$, dass sie nicht im Büro ist. I know that she not in office is

'I know that she is not in the office.'

c. A: Couldn't it be hiding in the drawer? Or under the carpet?

d. B: Nein, ich weiß genau, dass sie nicht im no I know GENAU that she not in 'No, I definitely know that she is not in the office.'

Büro ist. office is 
B's utterance in (19a) allows A to challenge B's knowledge by bringing up Type 3 possibilities that might have been not considered by B, (19c). By uttering (19d) however, $B$ indicates the she has considered and excluded any possible not- $p$ world, even ones that could also be ignored. Hence, Ich wei $\beta$ dass $p$ sets a context where more exceptions are allowed. Ich weiß genau dass $p$, on the other hand, rules out further possibilities that become available via a widening of the set of worlds under consideration. As a result, any not-p possibility that can be excluded, is ruled out.

The idea suggested for genau is strongly reminiscent of another grammatical phenomenon, namely the domain widening function of any, first proposed by KADMON - LANDMAN (1993); cf. KRIFKA (1995), LAHIRI (1998), and CHIERCHIA (2006). In particular, they argue that the meaning of any widens the domain of quantification by widening the denotation of the NP along a contextually given dimension, demonstrated in (20). A's utterance in (20c) indicates a shift in what counts as 'owl', relative to what it might have been before: any owl can include something that an owl cannot.

(20) a. A: An owl hunts mice.

b. B: A sick owl does not hunt mice.

c. A: Wrong. ANY owl hunts mice.

The shift from bare wissen to genau wissen parallels this shift insofar as the set (of worlds and individuals, respectively) w.r.t. which the latter expressions are evaluated exceeds the one available in the former cases. Crucially, in the case of genau wissen, the exclusion of the elements that become available via the shift leads to the strengthening. Thus, genau wissen excludes something that wissen does not.

\section{Paraphrase: revised semantics of wissen}

As a final step, I provide an informal paraphrase for a revised semantics of wissen and define the impact of genau. To capture the idea that genau manipulates the set of worlds to be considered of certain verbs, this set has to be accessible for manipulation. Crucially, it cannot be limited to the subject's belief worlds, but needs to be expanded to worlds incompatible with some of the subject's beliefs. This means that apart from the belief worlds, other worlds that have various similar properties to the actual world have to be considered. Some of those are $p$-worlds, some are not- $p$ worlds. These worlds are sorted relative to whether the attitude holder regards them as candidates for the actual world. The more worlds are available to get sorted, the "better" the knowledge-which is precisely what the modifier reflects. This yields the following paraphrases for unmodified and modified wissen (in both cases, obviously, plus factivity presupposition): 
Let us consider that we need to determine whether $x$ wei $\beta$ dass $r$ is true in a world $w$. The set $A$, defined in $i$ ), is a technical construct necessary to precisely describe the intuition behind the set of worlds considered apart from the usual believe worlds. Worlds in $A$ are similar to $x$ 's belief worlds w.r.t. different aspects, importantly not w.r.t. the relevant proposition, the one that is known, here $r$. Thus, in $A$ there are worlds such that $p=1, q=1$ and $r=1$ as well as worlds where $p=1, q=1$ and $r=0$.

i) A is the set of all $w^{\prime}$ that are similar to what $x$ believes in $w$, excluding $r^{10}$

ii) Based on $x^{\prime}$ 's evidence in $w, x$ can decide for all $w^{\prime}$ in $\mathrm{A}$, whether $w^{\prime}$ is in $x^{\prime}$ s belief worlds.

So, the particular evidence is sufficient for deciding on each world in A, whether it is compatible with what is believed. Thus, evidence functions as an ordering on worlds.

$x$ weiß dass $r$ holds iff

iii) for all $w^{\prime}$ in $A$, if not-r holds in $w^{\prime}$ it follows that from $x^{\prime}$ s evidence in $w$ it follows that $w^{\prime}$ is not in $x^{\prime}$ 's belief worlds $x$ weiß genau dass $r$ holds iff

iv) there is a proper superset of $A, A^{\prime}$ and for all $w^{\prime}$ in $A^{\prime}$, if not-r holds in $w^{\prime}$ it follows that from $x^{\prime}$ 's evidence in $w$ it follows that $w^{\prime}$ is not in $x^{\prime}$ 's belief worlds

The shift from bare wissen to genau wissen is reflected in an expansion of $A$, leading to a consideration of worlds that are somehow more far-fetched or further away from $w$ than those that need to be excluded anyway in order to use bare wissen. This widening is due to the fact that-based on a piece of evidence required in order to utter genau-more worlds can be sorted. Thus, genau does not refer to evidence directly. The effect of strengthening is a result of the extension of $A$ : the more worlds are available for ordering, the more can be excluded. The idea of "further away worlds" can be captured via Lewis' distinction between Type 1-needs to be excluded no matter what-and Type 3-can either be excluded or ignored-worlds: whereas A contains only of Type 1 worlds, $A^{\prime}$-which is a proper superset of A-contains of Type 1 and Type 3 worlds. ${ }^{11}$

10 Note that there is a huge body of literature on similarity relations (e.g., YALCIN 2007). As there are a lot of technical issues to be solved, I leave it at a paraphrase for now, which of course leaves several questions open.

11 As Lewis' Type 2 worlds-those that can only be ignored-are due to their nature ruled out by default, they do not occur in the paraphrase. 


\section{Conclusion}

I identified a class of attitude and perception verbs based on their compatibility with genau and suggested that the assertion of knowledge is the defining property of this class. After distinguishing two different readings of the modifier in embedding contexts, I focused on the one that arises in declarative contexts (d-reading). Here, the modifier seems to cause a strengthening of the relevant attitude, which in turn raises a problem for the traditional analysis of wissen. In connection to LEwIS (1996), I suggested that the contribution of genau to wissen is to actually exclude possibilities that can be ignored when using bare wissen-an idea that entails the necessity of a revision of the traditional semantics of know. I proposed that this consideration of additional alternatives is based on a widening of the set of worlds to be considered, induced by the modifier. Finally, I provided a paraphrase for $x$ wei $\beta$ dass $p$ and $x$ weiß genau dass $p$, respectively, that relates to the set of worlds similar to $x$ 's belief worlds and an extension thereof.

The notion of relevant alternatives in the context of know is also found in KRATZER'S (2001) approach. Embedded in situations semantics she provides a paraphrase of knowledge ascription that is among other things enriched by the requirement that ' $x$ can rule out relevant alternatives of a situation $s$ that do not exemplify $p$ '. By appealing to relevant alternatives, the paraphrase encodes the possibility of context dependency (and, arguably via the latter, vagueness)-a trait Kratzer considers to be a crucial component of the meaning of know. While the intuition behind Kratzer's idea seems relevant for the issue discussed here, it is not completely clear to me how it could be implemented.

Though, w.r.t. a compositional analysis, the question whether the relevant alternatives should be identified with worlds, propositions or situations will be left open here. Two crucial questions in this respect concern i) the exact analysis of the other verbs compatible with the modifier and ii) what style of analysis captures other aspects of the semantics of wissen best, e.g., the distinction from glauben. Furthermore, it would be interesting to investigate the claim regarding the presence of a set of attitude verbs distinguishable via the generalization in Section 3.2, whose members behave similar w.r.t. specific phenomena, cross-linguistically.

\section{REFERENCES}

Beltrama, Andrea. 2018. Totally between subjectivity and discourse: Exploring the pragmatic side of intensification. Journal of Semantics 35(2), pp. 219-261.

Chierchia, Gennaro. 2006. Broaden your views: Implicatures of domain widening and the logicality of language. Linguistic Inquiry 37, pp. 535-590.

DJÄRv, Kajsa - ZEHR, Jérémy - SchWARZ, Florian. 2018. Cognitive vs. emotive factives: An experimental differentiation. In: Proceedings of Sinn und Bedeutung 21(1), pp. 367-386. 
GetTier, Edmund. 1963. Is justified true belief knowledge? Analysis 23, pp. 121-123.

Geurts, Bart. 2006. Take 'five'. In: VogeleER, Svetlana - TASmowski, Liliane, eds. Non-definiteness and Plurality. Amsterdam: John Benjamins, pp. 311-329.

Goldman, Alvin. 1976. Discrimination and perceptual knowledge. The Journal of Philosophy 73, pp. 771-79.

Hintikka, Jaakko. 1969. Semantics for Propositional Attitudes. In: Davis, John Whitney Hockney, Donald James - Wilson, W. Kent, eds. Philosophical Logic. Springer, pp. 21-45.

Horn, Laurence. 1972. On the Semantic Properties of the Logical Operators in English. PhD thesis, University of California.

Kadmon, Nirit - Landman, Fred. 1993. Any. Linguistics and Philosophy 16(4), pp. 353-422.

KARTtunen, Lauri. 1977. Syntax and semantics of questions. Linguistics and Philosophy 1(1), pp. 3-44.

KipARsky, Paul - Kiparsky, Carol. 1970. Fact. In: Bierwisch, Manfred - Heidolph, Karl Heinrich, eds. Progress in Linguistics. De Gruyter, pp. 143-173.

Kratzer, Angelika. 2001. Facts: Particulars or information units? Linguistics and Philosophy 25(5), pp. 655-670.

KRIFKA, Manfred. 1995. The semantics and pragmatics of polarity items. Linguistic Analysis 25, pp. 209-257.

LAHIRI, Utpal. 1998. Focus and Negative Polarity in Hindi. Natural Language Semantics 6, pp. 57-123.

LANGENDOen, Donald - SAVin, Harris. 1971. The projection problem for presuppositions. In: Fillmore, Charles - Langendoen, D. Terence, eds. Studies in Linguistic Semantics. New York: Holt, Rinehart and Winston, pp. 44-60.

LASERSohn, Peter. 1999. Pragmatic halos. Language 3(75), pp. 522-551.

LEvinson, Stephen. 1983. Presumptive Meanings. Cambridge, MA: MIT Press.

LEwis, David. 1996. Elusive knowledge. Australasian Journal of Philosophy 74(4), pp. 549-567.

MorzYCKI, Marcin. 2011. Metalinguistic comparison in an alternative semantics for imprecision. Natural Language Semantics 19(1), pp. 39-86.

Sauerland, Uli - Stateva, Penka. 2007. Scalar vs. epistemic vagueness: Evidence from approximators. In: Proceedings of SALT 17, pp. 228-245.

YALCIN, Seth. 2007. Epistemic modals. Mind 116, pp. 983-1026.

Acknowledgment: Thanks to Nina Haslinger, Eva Rosina, Magdalena Roszkowski, Viola Schmitt, and Frank Sode, the audience of SinFonIJA 12 as well as two anonymous reviewers for helpful comments and support. This research was supported by the Austrian Science Fund (FWF) projects P-29240 and P-32939. 
Valerie Wurm

Distinguishing semantic components of attitude verbs via the German modifier genau

Valerie Wurm

Department of Linguistics

Sensengasse 3A, 1090 Vienna

University of Vienna

Austria

Department of German Studies

Mozartgasse 1, $8010 \mathrm{Graz}$

University of Graz

Austria

valerie.wurm@uni-graz.at 